\title{
International Council for Standardization in Haematology Recommendations for Hemostasis Critical Values, Tests, and Reporting
}

\author{
Robert C. Gosselin, $\mathrm{CLS}^{1}$ Dorothy Adcock, $\mathrm{MD}^{2}$ Akbar Dorgalaleh, $\mathrm{PhD}^{3}$ \\ Emmanuel J. Favaloro, PhD, FFSc (RCPA) ${ }^{4}$ Giuseppe Lippi, $\mathrm{MD}^{5}$ João M. Pego, MD 6 \\ Irene Regan, FRCPath, FACSLM ${ }^{7}$ Virginie Siguret, $\mathrm{PhD}^{8}$
}

1 Thrombosis and Hemostasis Center, University of California, Davis Health System, Sacramento, California

2 Laboratory Corporation of America, Burlington, North Carolina

${ }^{3}$ Department of Hematology and Blood Transfusion, School of Allied Medicine, Iran University of Medical Sciences, Tehran, Iran

${ }^{4}$ Department of Haematology, Sydney Centres for Thrombosis and Haemostasis, Institute of Clinical Pathology and Medical Research (ICPMR), NSW Health Pathology, Westmead Hospital, Westmead, New South Wales, Australia

${ }^{5}$ Dipartimento di Scienze Neurologiche e del Movimento, Sezione di Biochimica Clinica, Universita degli Studi di Verona, Verona, Italy

${ }^{6}$ Centro Hospitalar e Universitário de Coimbra, Coimbra, Portugal

${ }^{7}$ Coagulation Department, Our Lady's Children's Hospital, Crumlin, Dublin, Ireland

${ }^{8}$ Service d'hématologie Biologique, Hôpital Lariboisière, Université Paris Descartes, Paris, France

Semin Thromb Hemost 2020;46:398-409.
Address for correspondence Robert C. Gosselin, CLS, Thrombosis and Hemostasis Center, University of California, Davis Health System, Sacramento, CA 95817 (e-mail: rcgosselin@ucdavis.edu).
Abstract
Keywords
- hemostasis
- coagulation
- critical values
- critical tests
- laboratory practice

This guidance document was prepared on behalf of the International Council for Standardization in Haematology (ICSH), the aim of which is to provide hemostasisrelated guidance documents for clinical laboratories. The current ICSH document was developed by an ad hoc committee, comprising an international collection of both clinical and laboratory experts. The purpose of this ICSH document is to provide laboratory guidance for (1) identifying hemostasis (coagulation) tests that have potential patient risk based on analysis, test result, and patient presentations, (2) critical result thresholds, (3) acceptable reporting and documenting mechanisms, and (4) developing laboratory policies. The basis for these recommendations was derived from published data, expert opinion, and good laboratory practice. The committee realizes that regional and local regulations, institutional stakeholders (e.g., physicians, laboratory personnel, hospital managers), and patient types (e.g., adults, pediatric, surgical) will be additional confounders for a given laboratory in generating a critical test list, critical value thresholds, and policy. Nevertheless, we expect this guidance document will be helpful as a framework for local practice. published online October 22, 2019
Issue Theme Editorial Compilation VIII; Guest Editors: Emmanuel ]. Favaloro, PhD, FFSc (RCPA), and Giuseppe Lippi, MD.
Copyright $\odot 2020$ by Thieme Medical Publishers, Inc., 333 Seventh Avenue, New York, NY 10001, USA. Tel: +1(212) 760-0888
License terms

(c) $(1) \ominus \$$ 
The concept of identifying laboratory values requiring both immediate laboratory and clinician intervention was originally proposed by George D. Lundberg, in 1972, ${ }^{1}$ who continued to provide his input into the field for several decades, ${ }^{2}$ and continues to be active today. The term "critical value" was coined as being a laboratory-generated test result "that represents a pathophysiological state at such variance with normal as to be life threatening unless something is done promptly and for which some corrective actions could be taken." 1,2 Shortly thereafter, in 1991, Gerald Kost provided some insights into how U.S. laboratories have addressed critical values. ${ }^{3}$ For those tests related to hemostasis, the survey delineated four basic hemostasis-related analyses, with a range of reported critical values, and comprising activated partial thromboplastin time (APTT; cited range, 32-150 seconds); prothrombin time (PT; cited range, 14-40 seconds); fibrinogen (cited two ranges, a low fibrinogen range of $0.50-1.00 \mathrm{~g} / \mathrm{L}$ and a high fibrinogen range of 5.0$10.0 \mathrm{~g} / \mathrm{L}$, respectively), and platelet count (cited two ranges, a low platelet count range of $10-100 \times 10^{9} / \mathrm{L}$ and a high platelet count range of $555-1000 \times 10^{9} / \mathrm{L}$, respectively). Notably, of these four tests in the Kost's U.S. laboratory survey, ${ }^{3}$ only the platelet count was considered in the original Lundberg proposal. Since the Kost report, ${ }^{3}$ several other studies and documents have been published around hemostasis critical values, based on either organizational surveys, 4,5 expert opinion, ${ }^{6,7}$ or local, institutional practices. ${ }^{8,9}$ What can be readily concluded from all these publications is the clear lack of agreement on which tests should be considered for inclusion, what constitutes a critical result threshold, as well as reporting and documenting mechanisms. The purpose of this International Council for Standardization in Haematology (ICSH) document is to provide laboratory guidance for (1) identifying hemostasis (coagulation) tests that have potential patient risk based on analysis, test result, and patient presentations, (2) critical result thresholds, (3) acceptable reporting and documenting mechanisms, and (4) developing laboratory policies. The basis for these recommendations was derived from published data, expert opinion, and good laboratory practice. The committee realizes that regional and local regulations, institutional stakeholders (e.g., physicians, laboratory personnel, hospital managers), and patient types (e.g., adults, pediatric, surgical) will be additional confounders for a given laboratory in generating a critical test list. This document is therefore not intended to mandate any regional or institutional requirements or definitions. Nevertheless, we expect this guidance document will be helpful as a framework for local practice.

\section{Definition of Terms}

There are a variety of terms that have been used to describe critical values, including "panic values," "alert values," and so on. For the purposes of this document, we have identified four terms that will be used throughout this guidance document.

Critical value (or limits): a test result that is clinically significantly outside the normal range (lower or upper), and may represent serious morbidity or life-threatening values, which requires immediate communication of results.

Critical or high-risk test result: a test that requires immediate or timely communication of results irrespective of whether they are normal, significantly abnormal, or marked as critical, since the patient may be at risk of death or serious injury (may be highly dependent on clinical context).

Critical test list: a list of laboratory-provided tests that may have associated critical values or critical test results.

Result threshold: a test value which is associated with either a critical value or a critical or high-risk test result.

Other terms that may be regionally developed (e.g., significant high-risk result, alert thresholds, alert lists) will not be addressed. Reference laboratories, due to lack of access to original clinical information, may have more robust critical test lists, with more conservative thresholds. Critical values are independent of clinical presentations, whereas critical results are highly dependent on clinical presentations.

\section{ICSH-Recommended Critical Test List}

The committee evaluated a vast number of hemostasisrelated assays, which included routine screening assays (e.g., PT, APTT), international normalized ratio (INR), other routine hemostasis tests (e.g., fibrinogen, D-dimer), and more esoteric assays that may be available at most clinical laboratories (e.g., factor assays, protein C; - Table 1). Only PT, APTT, platelet count, and fibrinogen achieved unanimous agreement in the critical test list. The platelet count will not be considered in this document, as this was addressed in a previously published ICSH document on hematology critical values. ${ }^{10}$ The other tests listed in this guidance document were based on majority consensus, with most of these tests being considered in the clinical context and falling under the category of a critical or high-risk test result. The rationale for inclusion of nonconsensus tests in the critical test list will be discussed. The committee also considered the notion that clinicians may become inured to the seriousness of critical tests, if too many are created by the clinical laboratory.

The committee concluded that critical value tests include PT/INR, APTT, fibrinogen, heparin-induced thrombocytopenia (HIT) test, selective factor activities, factor inhibitor assay, von Willebrand factor (VWF), and a disintegrin and metalloproteinase with a thrombospondin type 1 motif, member 13 (ADAMTS13) levels. Critical result tests would include the aforementioned tests, albeit at different thresholds aligned with clinical presentations, along with drug assessment testing, including unfractionated heparin (UFH), low-molecular-weight heparin (LMWH), and direct oral anticoagulants (DOACs; - Table 2 ).

\section{ICSH-Recommended Critical Test List Thresholds (Critical Values)}

Critical values or test result may be triaged locally and by associated patient presentation. For example, an APTT of 60 seconds in a patient with active bleeding may be more 
Table 1 ICSH committee hemostasis critical test listing

\begin{tabular}{|c|c|c|}
\hline Test options & $\begin{array}{l}\text { Unanimous } \\
\text { consensus }\end{array}$ & $\begin{array}{l}\text { Majority } \\
\text { consensus }\end{array}$ \\
\hline APTT & APTT & HIT test \\
\hline Prothrombin time/INR & $\begin{array}{l}\text { Prothrombin } \\
\text { time/INR }\end{array}$ & Factor II \\
\hline Mixing studies & Fibrinogen & Factor $\mathrm{V}$ \\
\hline Fibrinogen (functional) & Platelet count & Factor VII \\
\hline Thrombin time & & Factor VIII \\
\hline D-dimer & & Factor IX \\
\hline Ecarin clotting time & & Factor $\mathrm{X}$ \\
\hline FDP/FSP & & Factor XI \\
\hline HIT test & & Factor XIII \\
\hline Factor II & & Inhibitor assay \\
\hline Factor V & & VWF activity \\
\hline Factor VII & & Anti-Xa-UFH \\
\hline Factor VIII & & Anti-Xa-LMWH \\
\hline Factor IX & & Apixaban \\
\hline Factor $\mathrm{X}$ & & Betrixaban \\
\hline Factor XI & & Edoxaban \\
\hline Factor XII & & Rivaroxaban \\
\hline Factor XIII & & Dabigatran \\
\hline HMWK/prekallikrein & & ADAMTS-13 \\
\hline \multicolumn{3}{|l|}{ Inhibitor assay } \\
\hline \multicolumn{3}{|l|}{$\begin{array}{l}\text { Protein C } \\
\text { (age adjusted) }\end{array}$} \\
\hline \multicolumn{3}{|l|}{$\begin{array}{l}\text { Protein S } \\
\text { (age adjusted) }\end{array}$} \\
\hline \multicolumn{3}{|l|}{$\begin{array}{l}\text { Antithrombin } \\
\text { (age adjusted) }\end{array}$} \\
\hline \multicolumn{3}{|l|}{ Lupus anticoagulant } \\
\hline \multicolumn{3}{|l|}{$\begin{array}{l}\text { Anticardiolipin } \\
\text { antibodies }\end{array}$} \\
\hline \multicolumn{3}{|l|}{$\begin{array}{l}\text { Anti-B2 glycoprotein I } \\
\text { antibodies }\end{array}$} \\
\hline \multicolumn{3}{|l|}{ VWF activity } \\
\hline \multicolumn{3}{|l|}{ VWF antigen } \\
\hline \multicolumn{3}{|l|}{ VWF multimers } \\
\hline \multicolumn{3}{|l|}{ Plasminogen } \\
\hline \multicolumn{3}{|l|}{ Alpha-2-antiplasmin } \\
\hline \multicolumn{3}{|l|}{ Platelet count } \\
\hline \multicolumn{3}{|l|}{ Platelet function screen } \\
\hline \multicolumn{3}{|l|}{ Platelet aggregation } \\
\hline \multicolumn{3}{|l|}{ Platelet flow cytometry } \\
\hline \multicolumn{3}{|l|}{ Thromboelastometry } \\
\hline \multicolumn{3}{|l|}{ Anti-Xa-UFH } \\
\hline \multicolumn{3}{|l|}{ Anti-Xa-LMWH } \\
\hline \multicolumn{3}{|l|}{ Anti-Xa-pentasaccharide } \\
\hline \multicolumn{3}{|l|}{ Apixaban } \\
\hline \multicolumn{3}{|l|}{ Betrixaban } \\
\hline \multicolumn{3}{|l|}{ Edoxaban } \\
\hline \multicolumn{3}{|l|}{ Rivaroxaban } \\
\hline \multicolumn{3}{|l|}{ Dabigatran } \\
\hline ADAMTS-13 & & \\
\hline
\end{tabular}

Abbreviations: ADAMTS, a disintegrin and metalloproteinase with thrombospondin type 1 motif; APTT, activated partial thromboplastin time; FDP, fibrin(ogen) degradation products; FSP, fibrin(ogen) split products; HIT, heparin-induced thrombocytopenia; HMWK, high-molecular-weight kininogen; INR, international normalized ratio; LMWH, low-molecular-weight heparin; UFH, unfractionated heparin; VWF, von Willebrand factor. critical than an APTT of 125 seconds in a clinically asymptomatic patient. The former patient may have underlying (clinically significant) factor deficiency (acquired or inherited), excessive drug effect, etc., whereas the latter patient may have a lupus anticoagulant or a contact factor deficiency (e.g., factor XII), which is clinically silent. As another example, a patient on apixaban with an INR of 3.0 would suggest greater risk from drug overexposure than a patient on oral vitamin K antagonist (VKA) therapy with an INR of 5.0. As such, defining critical thresholds for screening tests may not be considered a safety net for all potential uses of those tests and all patient clinical presentations. Thresholds for global hemostasis screening tests (PT and APTT) should be determined locally, based on instruments, reagents, and institutional patient populations. Various critical values or test results can be mined from online searching from various U.S. reference and clinical laboratories, ${ }^{11-15}$ but the cited thresholds are typically different, and it is generally unclear what instrument/reagent system is employed, thus making transference of screening test thresholds to other laboratories tenuous. The salient emphasis throughout this document should be the connection between physician request (what clinical presentation predicated the test being ordered?) and test result (does the result rise to a level that can be defined as a critical value or test based on the aforementioned clinical presentation?). The committee rationale for test designation is as follows.

\section{Rationale for PT/INR and APTT Designation}

Worldwide, the PT and APTT are the most commonly performed hemostasis tests. These analyses are used to assess general hemostasis status (e.g., procoagulant factor levels and function), as well as serve for monitoring anticoagulant therapy (e.g., oral VKAs, UFH) or replacement therapy (e.g., fresh frozen plasma or factor-specific replacement). Given the multiple functionalities of these tests, creating a single threshold may be difficult for addressing differing utilizations. For monitoring therapy, the patient bleeding risk should be clinically assessed using scoring models (e.g., HAS-BLED), which may signify a variable therapeutic target in a high-risk patient. ${ }^{16,17}$ The critical value thresholds reported for INR generally vary from 4.0 to $6.0,{ }^{3,4,7,8,17,18}$ but sometimes may even be as high as $10 .^{6}$ The emphasis for original inclusion of PT/INR in critical lists was based on oral VKAs and arising bleeding risk. The critical values for APTT are even more widely disparate, indicating a need for local determination of the critical threshold. Bleeding risks for UFH-treated patients were identified with discordant APTT to heparin levels, ${ }^{19}$ but no APTT recommendations were made for determining critical or high-risk results in a recent guidance document. ${ }^{20} \mathrm{~A}$ recent study demonstrated that the PT/INR, but not the APTT, was a high predictor for 30-day mortality. ${ }^{21}$ For APTT, there is a greater degree of variation, as unlike the PT with the INR there is no general standardization or normalization of the clotting time to mitigate differences between instrument and reagent sensitivity to UFH and factor deficiencies, although generation of APTT ratios may in part provide some solutions. ${ }^{6}$ However, it is 
Table 2 Guidance recommendations for hemostasis critical values and critical tests thresholds

\begin{tabular}{|c|c|c|c|}
\hline Test & Critical value & Critical test & Comments \\
\hline $\mathrm{PT} / \mathrm{INR}$ & Between 4.0 and $6.0^{a}$ & $\begin{array}{l}\text { In the setting of acute manage- } \\
\text { ment or related to therapy }\end{array}$ & $\begin{array}{l}\text { Critical value is for patients on vitamin } \\
\mathrm{K} \text { antagonist therapy }\end{array}$ \\
\hline APTT & To be locally determined & $\begin{array}{l}\text { In the setting of acute } \\
\text { management or posttherapy }\end{array}$ & $\begin{array}{l}\text { Threshold determination based on } \\
\text { reagent type and factor sensitivity, and } \\
\text { heparin response. Discussion with } \\
\text { stakeholders for identifying the critical } \\
\text { value is recommended. }\end{array}$ \\
\hline Fibrinogen & $\begin{array}{l}\text { Between } \leq 0.5 \text { and } \\
2.0 \mathrm{~g} / \mathrm{L}\end{array}$ & $\begin{array}{l}\text { In the setting of acute } \\
\text { management or posttherapy }\end{array}$ & $\begin{array}{l}\text { The critical value threshold is dependent } \\
\text { on the patient's clinical condition, in- } \\
\text { cluding trauma and pregnancy }\end{array}$ \\
\hline $\begin{array}{l}\text { Factors II, V, VII, } \\
\text { VIII, IX, X, and XI }\end{array}$ & $<5 \mathrm{IU} / \mathrm{dL}$ & $\begin{array}{l}\text { Replacement therapy in a known } \\
\text { factor deficient patient during } \\
\text { emergent management } \\
\text { (e.g., surgery) may warrant } \\
\text { critical notification }\end{array}$ & $\begin{array}{l}\text { Samples below LLOQ should be reported } \\
\text { as a critical value if LLOQ } \geq 5 \mathrm{IU} / \mathrm{dL}\end{array}$ \\
\hline Factor XIII & $<3 \mathrm{IU} / \mathrm{dL}$ & $\begin{array}{l}\text { In the setting of emergency man- } \\
\text { agement (e.g., surgery) }\end{array}$ & $\begin{array}{l}\text { Samples below LLOQ should be reported } \\
\text { as a critical value if LLOQ } \geq 3 \mathrm{IU} / \mathrm{dL}\end{array}$ \\
\hline HIT test & Positive & $\begin{array}{l}\text { Possible, for confirmation tests or } \\
\text { test results received from refer- } \\
\text { ence laboratory }\end{array}$ & $\begin{array}{l}\text { Test must be used in conjunction with } \\
\text { pretest probability models. Local } \\
\text { confirmation with stakeholders about } \\
\text { method and testing algorithms for } \\
\text { confirmation may be appropriate. }\end{array}$ \\
\hline VWF & $<10-15 \mathrm{IU} / \mathrm{dL}$ & $\begin{array}{l}\text { In the setting of emergency } \\
\text { management (e.g., surgery), } \\
\text { pregnancy, postpartum, neonate }\end{array}$ & $\begin{array}{l}\text { VWF method would include either } \\
\text { functional and/or antigenic assays }\end{array}$ \\
\hline Inhibitor assay & $\begin{array}{l}\text { Detectable titer at first } \\
\text { presentation, or } \\
\text { High titers ( }>5 \mathrm{BU})\end{array}$ & $\begin{array}{l}\text { Possible, in a patient not respon- } \\
\text { sive to replacement therapy }\end{array}$ & \\
\hline $\begin{array}{l}\text { Anti-Xa } \\
\text { (UFH or LMWH) }\end{array}$ & $\begin{array}{l}>1.50 \mathrm{U} / \mathrm{dL} \text { for } \mathrm{UFH} \\
>2.00 \mathrm{U} / \mathrm{dL} \text { for } \mathrm{LMWH}\end{array}$ & $\begin{array}{l}\text { Possible, in a high bleeding risk } \\
\text { patient }\end{array}$ & $\begin{array}{l}\text { For LMWH, consider patient population, } \\
\text { dosing interval, collection time, and } \\
\text { therapeutic target }\end{array}$ \\
\hline $\begin{array}{l}\text { Direct oral } \\
\text { anticoagulants }\end{array}$ & See comments & $\begin{array}{l}\text { Any result in the context of acute } \\
\text { bleeding, trauma, stroke, emer- } \\
\text { gency surgery }\end{array}$ & $\begin{array}{l}\text { Discussion with local stakeholders to } \\
\text { determine whether critical value } \\
\text { thresholds should be determined }\end{array}$ \\
\hline ADAMTS-13 & $<20 \%$ & & \\
\hline
\end{tabular}

Abbreviations: APTT, activated partial thromboplastin time; BU, Bethesda unit; HIT, heparin-induced thrombocytopenia; IU, International unit; LLOQ, lower limit of quantitation; LMWH, low-molecular-weight heparin; PT/INR, prothrombin time/international normalized ratio; UFH, unfractionated heparin; VWF, von Willebrand factor.

${ }^{a}$ Committee recommends that each institution determine the INR critical value threshold, but the critical INR value should not be lower than 4.0, nor should the lowest threshold for a critical INR be higher than 6.0.

unclear whether these anticoagulant-related thresholds should also apply to other patients.

\section{ICSH Committee Recommendations for PT/INR and APTT}

- Each laboratory should consider PT/INR and APTT critical value thresholds in conjunction with stakeholder input. For utilization in monitoring anticoagulation, a critical test risk result threshold should be predicated in conjunction with patient's bleeding risk.

- Each laboratory should address appropriate PT/INR and APTT critical thresholds based on reagent performance for:

- Factor type and factor sensitivity.

- UFH or direct thrombin inhibitor monitoring, if applicable.

\section{Rationale for Fibrinogen Designation}

Patients with fibrinogen deficiency, defined as functional (or antigenic) levels less than the lower limit of the reference interval (e.g., $<1.5-2.0 \mathrm{~g} / \mathrm{L}$ ), may present with bleeding in tissues, muscles, and joints, spontaneous splenic ruptures, and intracranial hemorrhage (ICH). ${ }^{22-26}$ Severe hypofibrinogenemia is characterized by fibrinogen levels of $<0.5 \mathrm{~g} / \mathrm{L}$, whereas moderate hypofibrinogenemia is associated with fibrinogen levels between 0.5 and $1.5 \mathrm{~g} / \mathrm{L}$. There is a good correlation between fibrinogen level and severity of clinical presentations. The bleeding risk also increases with trauma, pregnancy, and surgery (especially cranial), with fibrinogen levels $<2.0 \mathrm{~g} / \mathrm{L},{ }^{22,24,25}$ although patients with congenital fibrinogen deficiencies are often asymptomatic when fibrinogen is $>1.0 \mathrm{~g} / \mathrm{L}{ }^{26}$ Often, fibrinogen levels are used as triggers 
for replacement therapy, including cryoprecipitate and plasma-derived fibrinogen concentrates. ${ }^{22,25,26}$ Fibrinogen deficiency is associated with pregnancy loss, ${ }^{25}$ and therefore it is suggested that fibrinogen levels must be $>0.5 \mathrm{~g} / \mathrm{L},>1 \mathrm{~g} / \mathrm{L}$, and $>1.5 \mathrm{~g} / \mathrm{L}$ or $>2.0 \mathrm{~g} / \mathrm{L}$ during the first two trimesters, at the end of pregnancy, and during the peripartum period, respectively. ${ }^{27}$ Elevated fibrinogen is not an uncommon occurrence, given this protein is an acute-phase reactant. Persistently elevated fibrinogen has been associated with thrombotic risk. Given the relative frequency of elevated fibrinogen levels, and poor predictability with outcomes, the committee opted not to consider elevated levels as a critical result.

\section{ICSH Committee Recommendations for Fibrinogen}

- A fibrinogen level between 0.5 and $2.0 \mathrm{~g} / \mathrm{L}$ should be considered a critical test result, predicated on patient clinical presentation.

- The committee recognizes that low normal fibrinogen levels are approximately $1.5 \mathrm{~g} / \mathrm{L}$, thus overlapping between normal fibrinogen and a potential critical fibrinogen test result in select populations (e.g., trauma, pregnancy) may be problematic. A communication between stakeholders and laboratory is imperative to develop a mechanism for identifying select patient populations to assure timely reporting of critical fibrinogen test results.

- A fibrinogen level of $<1.0 \mathrm{~g} / \mathrm{L}$ could be considered a critical value if presenting in the third trimester of pregnancy in consideration of postpartum bleeding risk.

\section{Rationale for Factor II, V, VII, VIII, IX, X, XI, and XIII Designation}

There is a large heterogeneity of clinical presentations in patients with factor deficiencies, although major bleeding such as ICH is a notable risk for individuals with factor II, VII, VIII, IX, X, and XIII deficiencies. ${ }^{28}$ Although ICH can be spontaneous, the risk for bleeding increases after trauma, surgery, or other invasive procedures. Bleeding risk is well known for hemophilia A (factor VIII deficiency) and hemophilia B (factor IX deficiency). Hemophilia A patients with factor VIII $>20 \mathrm{IU} / \mathrm{dL}$ were associated with less bleeding events than those with lower levels. ${ }^{29}$ Factor IX levels of $>5 \mathrm{IU} / \mathrm{dL}$ rarely manifest spontaneous bleeding. ${ }^{30}$ For rare bleeding disorders (RBDs), the reported levels associated with spontaneous bleeding risk are factor II levels of $<5 \mathrm{IU} / \mathrm{dL}$, factor $\mathrm{V}$ levels of $<1$ IU/dL, factor VII levels $<8 \mathrm{IU} / \mathrm{dL}$, factor $\mathrm{X}$ levels of $<10 \mathrm{IU} / \mathrm{dL}$, and undetectable levels (or below the lower limit of quantitation, LLOQ for a given method) for factor XIII. $^{31,32}$ Others have established high risk for bleeding in patients with factor VII levels of $<2 \mathrm{IU} / \mathrm{dL}^{33}$ or $<3 \mathrm{IU} / \mathrm{dL}^{34,35}$ In women, low factor XIII activity is also associated with pregnancy loss, ${ }^{36}$ and a median factor XIII of $12 \mathrm{IU} / \mathrm{dL}$ (3-70 IU/dL) during pregnancy and a median factor XIII of $35 \mathrm{IU} / \mathrm{dL}$ (19-62 IU/dL) during labor ensured successful delivery. ${ }^{37,38}$ There is no clear association of factor XI levels with bleeding risk, but in these (formerly termed) "hemophilia C" patients, the bleeding risk may be associated with fibrin polymerization and stability. ${ }^{39}$ The committee recognizes that factor activities may be both a critical value (first-time diagnosis) and a critical test result (e.g., intraoperative test results). Various confounders are also recognized. The recommendations for coagulation factors are typically reflective of congenital deficiencies. VKA therapy will lead to low apparent levels of vitamin K dependent factors (FII, FVII, FIX, and FX). DOAC and UFH therapy may yield spuriously low levels of factors if these are tested.

\section{Additional Committee Recommendations Regarding Coagulation Factors}

- Critical test thresholds for factor levels are highly dependent on clinical presentation and clinical need (e.g., type of invasive procedure, type of anesthesia, etc.), and thus these thresholds should be determined locally in conjunction with stakeholders (e.g., hematologists, anesthesiologists, surgeons).

\section{Rationale for Heparin-Induced Thrombocytopenia Assay Designation}

HIT is a clinical paradox, where an immune response to the heparin/platelet factor 4 (PF4) complex during heparin anticoagulation in some patients gives rise to increased arterial or venous thrombotic (or even both) risk rather than bleeding risk. $^{40-42}$ The test is recommended in conjunction with assessing the patient's pretest probability, the most commonly applied being the 4T score, but other scoring methods have also been described (e.g., Chang score, HIT expert probability score) ${ }^{42}$ Failure to recognize HIT in patients may lead to severe morbidity (e.g., limb loss) or mortality. Recent guidelines recommend alternative (nonheparin) treatment in patients with T4 intermediate probability score and positive HIT testing. ${ }^{42,43}$

\section{Rationale for von Willebrand Factor Designation}

The bleeding risk associated with von Willebrand disease (VWD) is closely associated with the severity of VWF deficiency, ${ }^{44,45}$ and includes $\mathrm{ICH}^{28}$ and postpartum hemorrhage. ${ }^{46}$ Acquired VWD is associated with a variety of conditions including patients with ventricular assist devices, aortic stenosis, other high shear conditions, antibody-mediated conditions, and comorbid conditions (e.g., neoplasia), to name a few. The challenges for diagnosing VWD include variability of low VWF levels and bleeding risk ${ }^{44}$ as well as the limitations of the laboratory testing, including poor precision, poor sensitivity, or limits of quantitation for low levels. ${ }^{47}$ There was a noted correlation between bleeding symptoms and VWF antigen (VWF:Ag) and/or ristocetin cofactor (VWF:RCo) levels of $<10 \mathrm{IU} / \mathrm{dL}$, although it was unclear whether those patients represented type 3 or severe type $1 \mathrm{VWD}$, due to limitation of the LLOQ related to either the VWF:RCo or VWF:Ag methods. ${ }^{44}$ Modest reductions (30$50 \mathrm{IU} / \mathrm{dL}$ ) of VWF have some limited association with bleeding, whereas VWF levels of $<20$ IU/dL are "generally consistent with diagnosis" of VWD and associated increased bleeding risk. ${ }^{45}$ However, if an invasive procedure or a surgery is planned, target minimal VWF levels should be adapted upwards. 


\section{Rationale for Factor Inhibitor Assay Designation}

Alloantibodies directed against replacement factor in patients with hemophilia represents a severe complication of treatment, which may require either alternative treatment strategies (e.g., immune tolerance induction, ITI) or different treatments to control bleeding (e.g., recombinant activated factor VII). ${ }^{48}$ Inhibitor formation has other consequences such as anaphylaxis or severe allergic reactions after FIX infusion, occurring in about half of patients with hemophilia $\mathrm{B}$ and an inhibitor. Although inhibitor formation is a relatively common complication in patients with hemophilia A and $B$, it is an extremely rare complication in RBD that can change the treatment strategy. Acquired hemophilia due to factor VIII inhibitor most often presents with subcutaneous bleeding, gastrointestinal and muscle bleeding, and is more likely in older patients ( $>65$ years $)^{49}$ or during the peripartum period. Patients with underlying cancer and acquired hemophilia represent a higher risk for mortality as they typically have high inhibitor titer results. In patients with acquired hemophilia due to autoantibodies, high titers ( $>5.0$ Bethesda units $[\mathrm{BU}])$ were associated with bleeding that required more intervention (e.g., plasma exchange) than ITI. ${ }^{50}$ Also noted was the high risk of mortality associated with untreated patients with inhibitors prior to surgical or other interventions. ${ }^{50}$

\section{Rationale for Anti-Xa Levels for Unfractionated or Low- Molecular-Weight Heparin}

\section{Designation}

There is little evidence to support the current monitoring practice of UFH treatment, as the evidence is particularly weak, being based on small clinical trials. ${ }^{20,51}$ There are little data to support the use of critical values for these assays, although it is generally appreciated that increasing heparin levels increases bleeding risk. As such, the committee considers these tests to be considered potential critical tests. In a small series of patients, an antiactivated factor $\mathrm{X}(\mathrm{Xa})$ value of $>1.0 \mathrm{U} / \mathrm{mL}$ at 4 hours after initiation of heparin infusion was associated with higher bleeding risk, although anti-Xa measurements in general were not associated with bleeding risk. ${ }^{52}$ It should be appreciated that the application of adult UFH targets in pediatric patients may not be suitable, as anti-Xa critical targets for pediatric patients may not be similar to adult patients. ${ }^{53}$ The committee considered that an appropriately collected UFH/LMWH sample (4-6 hours after administration or dose adjustment) twice the upper limit of anti-Xa target should be considered as a potential critical result, with the understanding that this target may be influenced by patient's overall bleeding risk, ${ }^{16,17}$ age, and other considerations.

\section{Rationale for Direct Oral Anticoagulant Designation}

As a rule of thumb DOACs do not require routine monitoring in the same context as oral VKAs. However, it has been noted that urgent DOAC measurements may be useful in certain populations, including surgery, trauma, acute stroke, unexpected thrombosis, etc. ${ }^{54,55}$ Whether to measure DOAC levels prior to surgery or invasive procedures in lieu of a
24 to 48 wait period depending on the last dose is controversial, ${ }^{56}$ with a recent recommendation suggesting that such testing would be beneficial, due to ease of testing methods, relatively low cost, and assuredness for medicolegal cases. ${ }^{57,58}$ Recommendations are being considered in absence of DOAC level measurements (PAUSE study), which may be an acceptable practice for nonemergent surgery. ${ }^{59}$ Thresholds for safe surgery or thrombolysis in acute stroke have been proposed to be 30 to $50 \mathrm{ng} / \mathrm{mL}$ depending on patient presentation. ${ }^{60}$ Reversal strategies (e.g., andexenet $\alpha$ ) may not require DOAC measurements, but levels could guide physicians to dosing requirements. Praxbind will inhibit up to $1,000 \mathrm{ng} / \mathrm{mL}(0.001 \mathrm{~g} / \mathrm{L})$ of dabigatran, whereas there are two dosing strategies for andexanet alfa. The committee considers that DOAC test results should be considered critical in the context of the patient clinical presentation, especially in the acute bleeding setting or patient requiring thrombolysis for acute stroke.

\section{Rationale for ADAMTS-13 Activity Test Designation}

In conjunction with patient's clinical presentation, lactate dehydrogenase level, and platelet count, the ADAMTS-13 activity is a primary test used to determine the presence of thrombotic thrombocytopenic purpura (TTP) and to distinguish this from other microangiopathic hemolytic anemias that may require different therapeutic treatments. TTP, if left untreated, has a very high mortality rate, up to 85 to 95\%. The preferred treatment of TTP is plasma exchange, but even with this therapy, the mortality is still high, albeit reduced to 10 to $20 \% .{ }^{61}$

\section{Reporting and Documenting Critical Values or Test Values}

With regard to reporting and documenting critical values, there are some noted laboratory and clinical practice differences among countries, depending on organizational or regulatory agency recommendations. ${ }^{62,63}$ In the United States, the Joint Commission (TJC) has created National Patient Safety Goals (NPSG) for improving patient safety within health care institutions. For 2019, the TJC has reiterated the NPSG goal 2 (i.e., improving communication effectiveness among caregivers), which recommends improving the effectiveness of reporting critical test results among caregivers (NPSG.02.03.01). ${ }^{64}$ The underlying concept is to provide critical test results to responsible caregivers within a clearly defined timeframe, thereby allowing timely patient management. The cited elements of performance include the requirement for a written policy for critical results of tests and diagnostic procedures to include definitions, communication methods, timeliness, and monitoring effectiveness. ${ }^{64}$

TJC defines a critical test result as a value significantly falling outside the normal reference range, reflecting a potentially life-threatening condition, hence necessitating immediate communication. The International Organization for Standardization (ISO) ISO 15189:2012 standard, which addresses medical quality and competence in laboratories, also contains indications on critical value communications. ${ }^{62}$ In a 
summation of recommendations from regulatory agencies (TJC; Clinical and Laboratory Standards Institute, CLSI; Royal College of Pathologists, RCP; Italian Society of Clinical Biochemistry and Laboratory Medicine/Italian Society of Medicine, SIBIOC-SIMEL), Lippi and Mattiuzzi provided some summary recommendations, which basically propose (1) the essential elements for critical values or tests, and (2) the "best laboratory practice" from available consensus. ${ }^{62}$ Across organizations, an agreement was found that timely notification and read/call-back shall be mandatory elements of a critical value policy. However, recommendations for communication practices (e.g., to whom, by whom) were more regionally diverse.

In 2010, Piva and colleagues reported the critical value practice in Italy and the United States. From surveys, it was noted that only $63 \%$ of the respondents had written policies for critical values, with $90 \%$ describing time-frame limits, $62 \%$ read-back policy, $58 \%$ recording policy and, surprisingly, $21 \%$ being unaware of their reporting process. ${ }^{63}$ The reporting mechanisms included conventional telephone, computer, fax, or cell phones/tablets. Calls were initiated by laboratory managers (inclusive of pathologists, biologists, physicians on call, etc.) or other laboratory staff. The personnel receiving the calls included physicians, nurses, and/or clerical staff. In Italy, laboratory managers make the vast majority of critical value calls, whereas in the United States this duty is mostly left to laboratory technicians/technologists/scientists. Differences were also noted in the contacted person, whether inpatient (physician ordering test, registered nurse, or any ward staff) or outpatient (licensed caregiver or general practitioner). Recommendations from this publication included periodic surveillance to assess the rate of unsuccessful notifications and the development of an alternative strategy when primary caregivers cannot be readily contacted. ${ }^{63}$

Several authors have reported the use of electronic critical value notification systems. ${ }^{65-69}$ Guidi and colleagues described the implementation of one such system. Their policy provides on-board physician communication during determined (typically working) hours, whereas notification is accomplished by means of remote laptop communication when outside the laboratory or outside normal working hours (on call). ${ }^{65}$ This is a dual critical verification system: first within the laboratory information system (LIS) boundaries to assure sample viability and test-result quality, then second to emergency medical room with physician visual alert notification. This system requires laboratory physicians (or biologists) to confirm a critical value prior to result validation, and an on-call laboratory physician can remotely connect any time to a computer in the laboratory to access required information. Overall, a daily average of 161 notifications were reported and direct notification of clinician via telephone was minimal (2 per day, 1.2\%), thus demonstrating that the mean elapsed time from laboratory validation of the test result to physician acknowledgment (receipt) was 4 minutes (mean, standard deviation \pm 2 minutes). ${ }^{65}$ Piva and colleagues described a computerized notification procedure using hospital information system (HIS) and LIS. ${ }^{66}$ Within the LIS system, once a critical value is identified, the LIS then creates an email to the HIS system, which in turn generates two subsequent actions. The first is a short message service (SMS) to the ordering physician (or physician on duty), followed by a second department/ section alert flashing on the monitor for 60 minutes until addressed. Nevertheless, the authors concluded that SMS was not appropriate for emergency department (ED) notification. The highest frequency of critical values occurred in the hematology/hemostasis laboratory section, notable with platelet counts and APTT. Most critical values occurred during dayshift (7 AM to 4 PM). With a phone calling strategy, the average time taken for notification was 30 minutes, with a failure rate as high as $50 \%$. With the use of computerized notification, the average time was 11 minutes, and the failure rate reduced to only $10 \%{ }^{66}$ The use of informatics has reduced outpatient notification failure rates by using on-call physicians to validate all critical values, real-time notification using SMS, or alert messages on electronic platforms (computers, tablets, or cell phones). ${ }^{67}$ Singh and colleagues described their implementation of an electronic medical record (EMR) critical value notification method using "View Alert." ${ }^{68}$ However, they cite problems with the lack of clinician acknowledgment and timely follow-up resulting in the laboratory subsequently requiring to follow up where either the notification receipt was not acknowledged (10.2\%) or to confirm "undocumented follow-up actions" (79/1,163, 6.8\%). ${ }^{68}$ However, it was suggested that reducing the failure rate secondary to a PC-limited "View Alert" could be achieved by implementing the use of mobile phones over any EMR alert viewing system. ${ }^{69}$

The consensus recommendations for reporting ( - Table 3 ) and documenting ( - Table 4 ) critical values or critical test results encompass the following:

- Mandatory availability of a written policy for critical values or test results (see the next section).

- All critical values or locally determined critical test results require personal notification to the requesting physician or designated caregiver.

- The committee recommends a licensed or accredited caregiver be notified for critical values. For outpatients in the absence of a licensed or accredited caregiver, institutional surrogates as well as direct patient contact should be considered.

- All critical values or locally decided critical result notifications must occur $<1$ hour from result validation.

- The laboratory director designates who can/must report critical values.

- The institutional chief medical officer (or equivalent), in conjunction with any regulatory agency, regional, and/or institutional or compliance requirements, designates the categories of health care professional which can/must receive critical value results and critical test results.

- At a minimum, the following must be provided when calling a critical value or test result:

- Name and title of the person communicating the result (first and last name or ID).

- Title or role.

- Patient name (first and last).

- Medical record number (or equivalent). 
Table 3 Key elements for reporting hemostasis critical values or critical test results

\begin{tabular}{|l|l|}
\hline Element & Recommendation \\
\hline Notification & To primary caregiver or designated caregiver \\
\hline Notification timeframe & Within 1 hour of test verification or validation \\
\hline Who can generate notification & As designated by laboratory director \\
\hline Who can receive notification & $\begin{array}{l}\text { As designated by regulatory bodies, institutional chief medical officer, licensed or } \\
\text { accredited caregivers, laboratory director, institutional stakeholders, and potentially } \\
\text { direct patient contact }\end{array}$ \\
\hline $\begin{array}{l}\text { Minimum information } \\
\text { for verbal notification }\end{array}$ & $\begin{array}{l}\text { Full name and title of person providing notification, patient's full name and medical } \\
\text { record number (or equivalent secondary identification), blood sample collection } \\
\text { date and time, test name, and test result }\end{array}$ \\
\hline $\begin{array}{l}\text { Minimum information required for } \\
\text { assuring accuracy of verbal } \\
\text { communication }\end{array}$ & $\begin{array}{l}\text { Read back from notification recipient must include recipient's full name and title, } \\
\text { patient's full name and secondary identifier, and test result }\end{array}$ \\
\hline
\end{tabular}

Table 4 Key elements for documenting hemostasis critical values or critical test results

\begin{tabular}{|l|l|}
\hline Element & Recommendation \\
\hline Who can document notification & As designated by laboratory director \\
\hline $\begin{array}{l}\text { Minimum information for documentation } \\
\text { of verbal and/or electronic } \\
\text { recipient notification }\end{array}$ & $\begin{array}{l}\text { Full name and title (or role) of person receiving notification; patient's full } \\
\text { name and medical record number (or equivalent secondary identification), } \\
\text { test and test result read back }\end{array}$ \\
\hline $\begin{array}{l}\text { Minimum information required for } \\
\text { documenting a verbal and/ } \\
\text { or electronic communication }\end{array}$ & $\begin{array}{l}\text { Name and title of person communicating result (first and last name or ID), } \\
\text { name and title of person receiving result (first and last name or ID and title } \\
\text { or role, as noted above), date and time of communication, acknowledgment } \\
\text { of result-read back requirement }\end{array}$ \\
\hline
\end{tabular}

- Sample collection date and time.

- Test name (full name and abbreviation, as locally determined).

- Test result.

- Note: The person communicating the critical value or test result must be prepared to provide the test reporting unit and reference range upon request.

- At a minimum, when calling a critical value or test result, the following information must be provided and recorded from the recipient:

- Personal full name (first and last) or ID (according to local regulations on confidentiality).

- Title or role.

- Patient name (first and last).

- Patient medical record number (or secondary identification).

- Test and test result read back.

- At a minimum, the following elements must be recorded when documenting a verbal result communication:

- Name and title of the person communicating the result (first and last name or ID).

- Name and title of the person receiving the result (first and last name or ID and title or role, as noted above).

- Date and time of communication.

- Acknowledgment of test and test result, with read back requirement.
- The use of electronic means (Alert Views, mobile communication devices such as Vocera, SMS, or text messages to either PC, laptops, tablets, or cell phones) for communicating critical values or results must be validated to assure:

- Timeliness and accuracy of test result notification.

- Documentation of acknowledgment of result receipt by a designated receiver.

- Includes date and time of acknowledgment.

- Full name and title, if electronic device is shared with other users.

- And, an alternative strategy for critical value or result communication when untimeliness of notification or failed acknowledgment of result occurs.

- And, an alternative strategy when the designated electronic communication system for communicating critical values or results is nonoperational.

- Surveillance of institution's critical value or test notification mechanism must be episodically evaluated to determine system failure rate and subsequent impact on patient safety.

- A component of measuring quality indicators for the laboratory as required by ISO 15189: 2012 and the International Federation of Clinical Chemistry and Laboratory Medicine (IFCC). ${ }^{70}$

- Determination of critical value or critical test notification failure rate. 
- Turnaround times (TATs) for critical value or critical test result notifications.

- Regional or local regulatory agencies may dictate the required frequency of surveillance, but no less than quarterly (every 3 months).

\section{Guidance for Critical Values and Critical Test Policies}

It is mandatory to create, maintain, and have readily available (to laboratory staff, caregivers, and medical direction) a written policy for a notification process of critical values and critical tests. The laboratory director and/or designate are the responsible person(s) for creating a laboratory policy on critical values and critical tests. The policy must emphasize that this is a mandatory process for result notification of institutionally defined critical values or critical test results, which may be either verbal and/or electronic notification to a designated, license caregiver. The laboratory or institutional policy must address the following key components (- Table 5):

- Defining terms such as "critical tests," "critical values," and TATs.

- For critical tests, create a table listing those in-institution available tests, the results of which may be considered critical. These tests are often predicated on patient's clinical situation (e.g., acute bleeding, trauma) or patient's location (perioperative, ED).

- The policy should consider any age-related thresholds, as well as disease states (e.g., cancer, hemophilia) or patient conditions (e.g., pregnancy), and anticoagulant or antithrombotic therapy.

- Incorporate feedback and input from stakeholders (e.g., anesthesiologists, surgeons, medical directors) regarding potential tests, TAT limits, and potential result thresholds.

- In addition, consider predefined algorithms and/or decision trees regarding supplementary testing, including potential interference from recent drug exposure.

- For establishing critical values, create a table listing the hemostasis (or other section) tests and critical value thresholds, with consideration for clinical conditions as well as age-related thresholds. Consider whether the test listing should incorporate test results received from laboratories outside the institution.

- Describe the key elements ${ }^{59}$ in the notification process. Prior to notification, the policy should indicate any laboratory processes to exclude potential sources of errors (preanalytical and analytical) before communicating critical values or critical test results.

In addition, the notification process should address:

- Defining the notification timeframe to be within 1 hour of result confirmation or validation, regardless of the analytical methodology or patient location (e.g., hospitalized patient, outpatient).

- Defining who (within the laboratory section) is designated to call and/or electronically notify critical values or critical test results.

Table 5 Key components for a laboratory policy on notification of hemostasis critical values and critical tests

\begin{tabular}{|l|l|}
\hline Element & Policy considerations \\
\hline Definitions & Define critical value, critical test, and criteria for turnaround time \\
\hline Define and list critical tests & Internal (and external) hemostasis tests that may be considered critical \\
\hline Define and list critical value thresholds & Consider age and clinical conditions that may affect thresholds \\
\hline $\begin{array}{l}\text { Define laboratory algorithm for } \\
\text { verifying/validating critical value prior } \\
\text { to notification }\end{array}$ & $\begin{array}{l}\text { To be determined by regional regulatory agencies and/or laboratory director. } \\
\text { Laboratory should have a mechanism to exclude sources of error } \\
\text { prior to result reporting. }\end{array}$ \\
\hline $\begin{array}{l}\text { Define and list notification reporting } \\
\text { mechanism and criteria }\end{array}$ & Refer to - Table 2 \\
\hline $\begin{array}{l}\text { Define and list notification } \\
\text { documenting mechanism and criteria }\end{array}$ & Refer to - Table 3 \\
\hline $\begin{array}{l}\text { Define and determine quality indicators } \\
\text { of notification process }\end{array}$ & $\begin{array}{l}\text { Mechanism for reviewing the failure rates and turnaround times for notifications. } \\
\text { Refer to regional or regulatory requirements for frequency }\end{array}$ \\
\hline $\begin{array}{l}\text { Define and detail ancillary } \\
\text { notification processes }\end{array}$ & $\begin{array}{l}\text { Examples: (1) if electronic notification is implemented, a contingency plan when } \\
\text { that system is unavailable; (2) critical values received from, or reported to, } \\
\text { an outside facility }\end{array}$ \\
\hline Define policy reviewing process & $\begin{array}{l}\text { (1) Policy reviewed and approved by laboratory director at least annually or as } \\
\text { required by regional regulatory agencies; (2) annual policy reviewed (or when } \\
\text { policy changes) with attestation recorded, for all laboratory personnel that are } \\
\text { designated to call and receive notifications. }\end{array}$ \\
\hline $\begin{array}{l}\text { Other policy considerations } \\
\text { Repeat testing prior to result validation/verification; alternative approaches to } \\
\text { pecision made after receipt of notification; documentation retention period. }\end{array}$ \\
\hline
\end{tabular}


- Defining which licensed caregiver (or persons defined by institutional policy) is designated for receiving critical values or critical test results.

- The committee recommends a licensed or accredited caregiver be notified for critical values. For outpatients in the absence of a license or accredited caregiver, institutional surrogates as well as direct patient contact should be considered.

- Define an escalation or algorithmic process if the primary caregiver cannot be readily contacted.

- Define an escalation or algorithmic process if caregiver refuses to accept critical value or critical test results.

- Defining the minimum information the designated laboratory staff will provide to the caregiver, with at least the first and last name (or institutional ID) of the designated laboratory person who is communicating the value, the full name of patient and any secondary identifications such as medical record (preferred), or date of birth; the date and time of blood collection, test name, and test result.

- In addition,

- While abbreviations of common tests are acceptable (e.g., PT, APTT), the caller should be prepared for detailing the definition of the test abbreviation.

- Caller should be prepared to provide reference range if requested.

- Caller should be prepared to provide test units, if requested.

- Caller should be prepared to advice or secondarily refer the recipient for questions that may relate to therapeutic targets (e.g., contact pharmacy staff).

- Establish a requirement to have result recipient readback information to caller, including the patient's first and last name, secondary identifier, collection date and time, test name, and critical value or critical test result.

- Defining the documentation mechanism for critical value or critical test result notification. At a minimum, the notification documentation should include a manual or electronic record of the laboratory staff member (first and last name or institutional ID), date and time of the critical value or critical test notification, the caregiver's or recipient's first and last name (or institutional ID), professional title, and/or location, the patient's full name, secondary identifier, date and time of blood collection, the critical value critical test result (with units and reference range), and confirmation of read-back of the same.

- The policy should describe a surveillance program that requires episodic review of the critical value and critical test result notification. These quality indicators ${ }^{67}$ may be used:

- To determine the notification failure rate of critical values or critical test results.

- To determine the critical value or critical test notification TAT.

- If electronic notification is implemented, the policy must have a contingency plan when the electronic systems are nonoperational.
- If the laboratory provides services outside their institution, the policy must have a notification plan for those patient samples with results that fall within the institution's critical value threshold.

- This may be limited to laboratory communication.

- When possible, direct communication with patient's caregiver or location (e.g., hospital unit) would be preferred (this enables expert consultancy on test result).

- The critical value or critical test result policy must be reviewed at least annually or as mandated by regional or regulatory agencies, and after policy changes, and formally acknowledged by each laboratory staff member that has been designated to report and notify caregivers of critical values or critical test results.

- Electronic or manual documentation of acknowledgment policy is required.

- The critical value or critical test result policy should be systematically reviewed by the laboratory director or designate according to local certification/accreditation procedures or as required by regional or local regulatory agencies, or whenever new evidence (e.g., guidelines, recommendations) is published.

- Any changes in policy must have a document trail indicating that all parties (caregivers, laboratory staff, and medical direction) have read and acknowledged the policy changes.

Note: In addition, the committee recognizes, but takes no position, for additional considerations that may be in a laboratory critical value or test result notification policy. These additional considerations may include:

- Whether critical value results should be confirmed by repeat testing prior to notification.

- Whether there are modified notification approaches for patients with known critical values (e.g., serial monitoring of inhibitor titers in a patient with severe hemophilia A or B).

- Whether there are modified notification approaches for patients with repeated critical values within a designated time frame (e.g., 824 hours).

- Any clinical decisions that should be made after acknowledgment of a critical value or critical test result.

The retention of critical value or critical test notification reports must be defined (typically measured inyears) as required by regional or regulatory agencies.

\section{Conclusion}

Since many differing mechanisms are in place for critical value or critical test reporting, as well as there are different mechanisms for documenting critical values or critical test reporting, this ICSH document aims to provide some hopefully useful consensus recommendations for minimum 
hemostasis tests that are identified with critical values or critical test designation, and for minimum information required for critical value or critical test notification and documentation of notification process, as well as for the minimum requirements for a critical value or critical test laboratory policy to be helpful as a framework for local practice.

\section{Conflicts of Interest}

R.C.G. involved with expert testimony for dabigatran and rivaroxaban testing, served on advisory committees for Novo Nordisk and Roche Diagnostics, served as a consultant for Diagnostic Grifols, and received honoraria from Siemens Healthcare Diagnostics. D.A. received speaker's honorarium from Siemens Healthcare Diagnostics, serves as a consultant to Novo Nordisk and Bayer Pharmaceuticals. J.M.P. provided consulting for Horiba Medical and Snibe Co., Ltd. A.D., E.J.F., G.L., I.R., and V.S. report no disclosures.

\section{References}

1 Lundberg GD. When to panic over abnormal values. Med Lab Observer 1972;4:47-54

2 Lundberg GD. Critical (panic) value notification: an established laboratory practice policy (parameter). JAMA 1990;263(05):709

3 Kost GJ. Critical limits for urgent clinician notification at US medical centers. JAMA 1990;263(05):704-707

4 Pai M, Moffat KA, Plumhoff E, Hayward CP. Critical values in the coagulation laboratory: results of a survey of the North American Specialized Coagulation Laboratory Association. Am J Clin Pathol 2011;136(06):836-841

5 Wagar EA, Friedberg RC, Souers R, Stankovic AK. Critical values comparison: a College of American Pathologists Q-Probes survey of 163 clinical laboratories. Arch Pathol Lab Med 2007;131(12): 1769-1775

6 Lippi G, Adcock D, Simundic AM, Tripodi A, Favaloro EJ. Critical laboratory values in hemostasis: toward consensus. Ann Med 2017;49(06):455-461

7 Thomas L. Critical limits of laboratory results for urgent clinician notification, eJIFCC vol 14 no 1 . Available at: http://www.ifcc.org/media/477036/ejifcc2003vol14no1pp011-018.pdf. Accessed July 31, 2019

8 Hashim IA, Cuthbert JA. Establishing, harmonizing and analyzing critical values in a large academic health center. Clin Chem Lab Med 2014;52(08):1129-1135

9 Kopcinovic LM, Trifunović J, Pavosevic T, Nikolac N. Croatian survey on critical results reporting. Biochem Med (Zagreb) 2015;25(02):193-202

10 Keng TB, De La Salle B, Bourner G, et al; International Council for Standardization in Haematology (ICSH). Standardization of haematology critical results management in adults: an International Council for Standardization in Haematology, ICSH, survey and recommendations. Int J Lab Hematol 2016;38(05): 457-471

11 Associated Regional and University Pathologists (ARUP). Critical value test list. Available at: https://www.aruplab.com/Testing-In formation/resources/PDF_Brochures/ARUP_Critical_Values.pdf. Accessed July 31, 2019

12 Mayo Clinical Laboratories. Critical value list. Available at: https:// www.mayocliniclabs.com/it-mmfiles/DLMP_Critical_Values_-_Critical_Results_List.pdf. Accessed July 31, 2019

13 Quest Diagnostics. Laboratory priority value table. Available at: https://www.questdiagnostics.com/dms/Documents/test-center/
Quest_Diagnostics_Priority_Value_Tables.pdf. Accessed July 31, 2019

14 Stanford University Health Care. Critical/panic value list. Available at: https://stanfordhealthcare.org/health-care-professionals/laboratory-critical-value-list.html. Accessed July 31, 2019

15 University of Iowa. Critical laboratory tests and values. Available at: https://www.healthcare.uiowa.edu/path_handbook/Appendix/Com mon/UN_CRIT_LAB_VAL.html. Accessed July 31, 2019

16 Zhu W, He W, Guo L, Wang X, Hong K. The HAS-BLED score for predicting major bleeding risk in anticoagulated patients with atrial fibrillation: a systematic review and meta-analysis. Clin Cardiol 2015;38(09):555-561

17 Parks AL, Fang MC. Scoring systems for estimating the risk of anticoagulant-associated bleeding. Semin Thromb Hemost 2017; 43(05):514-524

18 Brigden ML, Kay C, Le A, Graydon C, McLeod B. Audit of the frequency and clinical response to excessive oral anticoagulation in an out-patient population. Am J Hematol 1998;59(01): 22-27

19 Price EA, Jin J, Nguyen HM, Krishnan G, Bowen R, Zehnder JL. Discordant aPTT and anti-Xa values and outcomes in hospitalized patients treated with intravenous unfractionated heparin. Ann Pharmacother 2013;47(02):151-158

20 Smythe MA, Priziola J, Dobesh PP, Wirth D, Cuker A, Wittkowsky AK. Guidance for the practical management of the heparin anticoagulants in the treatment of venous thromboembolism. J Thromb Thrombolysis 2016;41(01):165-186

21 Doering TA, Plapp F, Crawford JM. Establishing an evidence base for critical laboratory value thresholds. Am J Clin Pathol 2014;142 (05):617-628

22 Spahn DR, Spahn GH, Stein P. Indications and risks of fibrinogen in surgery and trauma. Semin Thromb Hemost 2016;42(02):147-154

23 Rodeghiero F, Tosetto A, Castaman G. How to estimate bleeding risk in mild bleeding disorders. J Thromb Haemost 2007;5(Suppl 1):157-166

24 Adelmann D, Klaus DA, Illievich UM, et al. Fibrinogen but not factor XIII deficiency is associated with bleeding after craniotomy. Br J Anaesth 2014;113(04):628-633

25 Casini A, de Moerloose P, Neerman-Arbez M. Clinical features and management of congenital fibrinogen deficiencies. Semin Thromb Hemost 2016;42(04):366-374

26 Casini A, de Moerloose P; Congenital Fibrinogen Disorders Group. Management of congenital quantitative fibrinogen disorders: a Delphi consensus. Haemophilia 2016;22(06):898-905

27 Dorgalaleh A, Cassini A, Rahmani P. Congenital fibrinogen disorders. In: Dorgalaleh A., ed. Congenital Bleeding Disorders - Diagnosis and Management. Cham: Springer Press; 2018:27-53

28 Tabibian S, Motlagh H, Naderi M, Dorgalaleh A. Intracranial hemorrhage in congenital bleeding disorders. Blood Coagul Fibrinolysis 2018;29(01):1-11

29 Valentino LA, Pipe SW, Collins PW, et al. Association of peak factor VIII levels and area under the curve with bleeding in patients with haemophilia A on every third day pharmacokinetic-guided prophylaxis. Haemophilia 2016;22(04):514-520

30 Konkle BA, Huston H, Nakaya Fletcher S. Hemophilia B. 2000 Oct 2 [updated 2017 Jun 15]. In: Adam MP, Ardinger HH, Pagon RA, Wallace SE, Bean LJH, Stephens K, Amemiya A, eds. GeneReviews ${ }^{\circledR}$ [Internet]. Seattle(WA): University of Washington, Seattle; 1993-2019. Available at: http://www.ncbi.nlm.nih.gov/books/NBK1495/. Accessed July 31, 2019

31 Girolami A, Ferrari S, Cosi E, Girolami B, Lombardi AM. Congenital prothrombin defects: they are not only associated with bleeding but also with thrombosis: a new classification is needed. Hematology 2018;23(02):105-110

32 Peyvandi F, Palla R, Menegatti M, et al; European Network of Rare Bleeding Disorders Group. Coagulation factor activity and clinical bleeding severity in rare bleeding disorders: results from the European Network of Rare Bleeding Disorders. J Thromb Haemost 2012;10(04):615-621 
33 Napolitano M, Siragusa S, Mariani G. Factor VII deficiency: clinical phenotype, genotype and therapy. J Clin Med 2017;6(04):E38

34 Di Minno MN, Dolce A, Mariani G; STER Study Group. Bleeding symptoms at disease presentation and prediction of ensuing bleeding in inherited FVII deficiency. Thromb Haemost 2013; 109(06):1051-1059

35 Di Minno MND, Napolitano M, Dolce A, Mariani G; STER Study Group. Role of clinical and laboratory parameters for treatment choice in patients with inherited FVII deficiency undergoing surgical procedures: evidence from the STER registry. Br J Haematol 2018;180(04):563-570

36 Bannow BS, Konkle BA. Inherited bleeding disorders in the obstetric patient. Transfus Med Rev 2018;32(04):237-243

37 Huq FY, Kadir RA. Management of pregnancy, labour and delivery in women with inherited bleeding disorders. Haemophilia 2011; 17(Suppl 1):20-30

38 Dorgalaleh A, Rashidpanah J. Blood coagulation factor XIII and factor XIII deficiency. Blood Rev 2016;30(06):461-475

39 Zucker M, Seligsohn U, Salomon O, Wolberg AS. Abnormal plasma clot structure and stability distinguish bleeding risk in patients with severe factor XI deficiency. J Thromb Haemost 2014;12(07): $1121-1130$

40 Warkentin TE. Heparin-induced thrombocytopenia. Curr Opin Crit Care 2015;21(06):576-585

41 Cuker A, Arepally GM, Chong BH, et al. American Society of Hematology 2018 guidelines for management of venous thromboembolism: heparin-induced thrombocytopenia. Blood Adv 2018;2(22):3360-3392

42 Favaloro EJ, McCaughan G, Pasalic L. Clinical and laboratory diagnosis of heparin induced thrombocytopenia: an update. Pathology 2017;49(04):346-355

43 Joseph J, Rabbolini D, Enjeti AK, et al. Diagnosis and management of heparin-induced thrombocytopenia: a consensus statement from the Thrombosis and Haemostasis Society of Australia and New Zealand HIT Writing Group. Med J Aust 2019;210(11):509-516

44 Metjian AD, Wang C, Sood SL, et al; HTCN Study Investigators. Bleeding symptoms and laboratory correlation in patients with severe von Willebrand disease. Haemophilia 2009;15(04):918-925

45 Sadler JE. Low von Willebrand factor: sometimes a risk factor and sometimes a disease. Hematology Am Soc Hematol Educ Program 2009:106-112

46 Hawke L, Grabell J, Sim W, et al. Obstetric bleeding among women with inherited bleeding disorders: a retrospective study. Haemophilia 2016;22(06):906-911

47 Favaloro EJ, Pasalic L, Curnow J. Laboratory tests used to help diagnose von Willebrand disease: an update. Pathology 2016;48 (04):303-318

48 Mancuso ME, Cannavo A. Immune tolerance induction in hemophilia. Clin Investig (Lond) 2015;5(03):321-335. Availabel at: https://www.openaccessjournals.com/articles/immune-tolerance-induction-in-hemophilia.pdf. Accessed August 23, 2019

49 Kruse-Jarres R, Kempton CL, Baudo F, et al. Acquired hemophilia A: updated review of evidence and treatment guidance. Am J Hematol 2017;92(07):695-705

50 Zeitler H, Ulrich-Merzenich G, Goldmann G, Vidovic N, Brackmann HH, Oldenburg J. The relevance of the bleeding severity in the treatment of acquired haemophilia - an update of a singlecentre experience with 67 patients. Haemophilia 2010;16(102): 95-101

51 Baluwala I, Favaloro EJ, Pasalic L. Therapeutic monitoring of unfractionated heparin - trials and tribulations. Expert Rev Hematol 2017;10(07):595-605
52 Nieuwenhuis HK, Albada J, Banga JD, Sixma JJ. Identification of risk factors for bleeding during treatment of acute venous thromboembolism with heparin or low molecular weight heparin. Blood 1991;78(09):2337-2343

53 Schechter T, Finkelstein Y, Ali M, et al. Unfractionated heparin dosing in young infants: clinical outcomes in a cohort monitored with anti-factor Xa levels. J Thromb Haemost 2012;10(03): 368-374

54 Douxfils J, Gosselin RC. Laboratory assessment of direct oral anticoagulants. Semin Thromb Hemost 2017;43(03):277-290

55 Gosselin RC, Adcock DM, Bates SM, et al. International Council for Standardization in Haematology (ICSH) recommendations for laboratory measurement of direct oral anticoagulants. Thromb Haemost 2018;118(03):437-450

56 Spyropoulos AC, Al-Badri A, Sherwood MW, Douketis JD. To measure or not to measure direct oral anticoagulants before surgery or invasive procedures: comment. J Thromb Haemost 2016;14(12):2556-2559

57 Tripodi A, Marongiu F, Moia M, et al. The vexed question of whether or not to measure levels of direct oral anticoagulants before surgery or invasive procedures. Intern Emerg Med 2018;13 (07):1029-1036

58 Tripodi A. To measure or not to measure direct oral anticoagulants before surgery or invasive procedures. J Thromb Haemost 2016; 14(07):1325-1327

59 Douketis JD, Spyropoulos AC, Anderson JM, et al. The Perioperative Anticoagulant Use for Surgery Evaluation (PAUSE) study for patients on a direct oral anticoagulant who need an elective surgery or procedure: design and rationale. Thromb Haemost 2017;117(12):2415-2424

60 Touzé E, Gruel Y, Gouin-Thibault I, et al. Intravenous thrombolysis for acute ischaemic stroke in patients on direct oral anticoagulants. Eur J Neurol 2018;25(05):747-e52

61 Zheng XL. ADAMTS13 and von Willebrand factor in thrombotic thrombocytopenic purpura. Annu Rev Med 2015;66:211-225

62 Lippi G, Mattiuzzi C. Critical laboratory values communication: summary recommendations from available guidelines. Ann Transl Med 2016;4(20):400

63 Piva E, Sciacovelli L, Laposata M, Plebani M. Assessment of critical values policies in Italian institutions: comparison with the US situation. Clin Chem Lab Med 2010;48(04):461-468

64 The Joint Commission. National Patient Safety Goals effective January 2019. Available at: https://www.jointcommission.org/ assets/1/6/NPSG_Chapter_HAP_Jan2019.pdf. Accessed March 12, 2019

65 Guidi GC, Poli G, Bassi A, Giobelli L, Benetollo PP, Lippi G. Development and implementation of an automatic system for verification, validation and delivery of laboratory test results. Clin Chem Lab Med 2009;47(11):1355-1360

66 Piva E, Sciacovelli L, Zaninotto M, Laposata M, Plebani M. Evaluation of effectiveness of a computerized notification system for reporting critical values. Am J Clin Pathol 2009;131(03):432-441

67 Lippi G, Plebani M. Informatics aids to reduce failure rates in notification of abnormal outpatient test results. Arch Intern Med 2009;169(19):1815-1817, author reply 1816-1817

68 Singh H, Thomas EJ, Sittig DF, et al. Notification of abnormal lab test results in an electronic medical record: do any safety concerns remain? Am J Med 2010;123(03):238-244

69 Piva E, Lippi G, Plebani M. Notification of abnormal and critical values: the road ahead. Am J Med 2010;123(10):e19, author reply e21

70 Plebani M, Sciacovelli L, Aita A. Quality indicators for the total testing process. Clin Lab Med 2017;37(01):187-205 